\title{
Justin Leidwanger: Roman Seas. A Maritime Archaeology of Eastern Mediterranean Economies
}

\author{
Oxford University Press, New York, 2020, 323 pp
}

\author{
Alkiviadis Ginalis ${ }^{1} \mathbb{D}$ \\ Accepted: 9 November 2021 / Published online: 1 December 2021 \\ (C) The Author(s) 2021
}

This book presents a comprehensive study of maritime interaction and historical network analysis based on underwater archaeological records from the northeastern Mediterranean. For the first time the Roman and Late Antique economy is being examined not just based on shipwreck data. Beyond the study of cargos and other aspects of seafaring, coastal landscapes, ports and diverse marine environments also find their way into "considerations of economy, exchange, mobility, regionalism, markets, and community identity" (viii). This aims for a different angle of illuminating longue durée developments of Mediterranean maritime communities, which eventually offers a deeper and more synthetic understanding of economic and social connectivity.

In six chapters the author approaches the perception of maritime contacts by contrasting the traditional ancient economic and maritime studies with the current state of archaeological records of the Eastern Mediterranean. The first chapter, "Maritime Interaction and Mediterranean Communities", provides a first critical analysis of means of connectivity through existing network studies such as that of Braudel, Horden and Purcell or Broodbank, adding also "scale" as a further aspect to be taken into account when discussing the development and character of markets. Since most socioeconomic models rely on datasets, Leidwanger correctly points to the problem of interpreting archaeological evidence and hence the weakness of databases. The latter often fail to reflect the different facets and complexity of the varied economies, especially when it comes to understand the time period of the second century BC to the seventh century AD. As such, by applying a variety of additional parameters, he tries to explain the way of understanding and using compilations of data such as Parker's corpus of shipwrecks.

This is followed up in chapter two, "Topography and Tools of Interaction", which is dedicated to the geographical and physical key parameters that affected ancient seafaring and coastal activities. Primarily, aspects of navigation like visibility, winds, tides and currents as well as a region's marine environment and coastal topography form the most relevant factors. As a response to the environmental, topographic but also economic, social and political impact to maritime activities, the author provides a nice overview of shipbuilding history throughout the Mediterranean. This includes recent research on types, sizes and the

Alkiviadis Ginalis

alkiviadis-alexandros.ginalis@ dainst.de

1 Istanbul Department, German Archaeological Institute (DAI), Istanbul, Turkey 
construction of ships, the rigging with the capabilities and manoeuvrability of sail types as well as seasonality, temporality, distances or journey times. The fact that the transition of nautical technology and seafaring practises from the Hellenistic to the Byzantine era did not follow a linear trajectory is shown both through archaeological evidence and different textual and iconographic sources.

Chapter three, "Modeling Maritime Dynamics", forms the theoretical framework for the ground methodological approach applied at the case studies along the Datça peninsula in southwestern Turkey and the southern coast of Cyprus. Leidwanger turns his attention to the concept of space and maritime topography. With a particular focus on the question of "regionalism" he examines the spatial use of landscapes and its reflection on maritime spheres and the formation of community identities. Based on Westerdahl's concept of "maritime cultural landscape" (77) as well as the works of Broodbank and Tartaron, the author tries to construct a model of maritime interaction that emphasizes different ways of "mobilities" such as trade, travel and even fishing. This opens a long needed discussion on the important role of even small scale or local roads, rivers and parts of the sea for the wider transportation network, which of course vary between time, area and actors. Thus, a differentiation between long distance-short haul, large scale-small scale and regularoccasional/seasonal activities illustrates a more complex picture of maritime connectivity throughout the Mediterranean.

With chapter four, "Exploring Shipwreck Data", the author reaches the core section of his book, where the theoretical methodology is finally applied to the dataset of wreck finds from his area under investigation. For the Roman and Late Antique periods this comprises a total number of 67 shipwrecks from his significantly reassessed and enriched catalogue (Appendix 1) based on older shipwreck databases like that of Parker. By shifting the focus from site locations to geographical links, one-mode and two-mode network visualizations are being produced. Within these, the author opposes Roman era to Late Antique data, which, among other information, shows a shift from single freights towards cargos from multiple areas. An ArcGIS-based analysis (145) eventually illuminates distances and related lengths of journeys. Taking into account the speed and direction of wind data or the capabilities of ships and sailors, this suggests new considerations for modelling ancient seafaring.

Chapter five, "Ports and Everyday Economies", turns the attention from shipwrecks to port sites as the second major aspect of maritime connectivity. Serving as "interface between land and sea", harbours formed "dynamic zones of social and economic contact" (154). In contrast to the traditional approach of considering exclusively major port sites and facilities instead of coves, sandy beaches or seasonal sites, the author again rightly argues for the importance of small facilities and bays for maritime economic networks. As such, he rather aims for a bottom-up study in order to reflect the entire range of coastal sites, including those he calls "inconspicuous" (159). After a first introduction into harbour studies and a rough definition of its facilities, Leidwanger again concentrates on the harbour situation along the Datça peninsula and the southern coast of Cyprus. Importantly, for these two case studies the detailed research extends even beyond coastal infrastructures, way into the hinterlands of the associated maritime communities.

The final chapter, "Maritime Networks in the Roman East", of this book merges the information gained from the shipwreck assemblages with that of port sites and their corresponding hinterlands. This offers for the first time a comprehensive synthesis of data with potential of producing accurate and not just superficial models of maritime economic networks throughout the Mediterranean and beyond. The chapter ends with the intention of putting the network data into the wider historical context of the Roman and Late Antique 
periods. Leidwanger eventually concludes chapter six and thus his book by remarking that network studies have to rely on many different "indicators of mobility, interaction and economic development throughout the hinterlands" (226).

With this book the author admirably masters a first deep insight into the complex world of Mediterranean economies. With the archaeological records indicating a diverse relationship and interdependency between economic networks and environmental, social and political impacts, a highly difficult task has been undertaken, especially for Late Antiquity. However, Leidwanger's work should not be taken as an ultimate study but rather as a starting point for new perspectives in maritime archaeology.

Funding Open Access funding enabled and organized by Projekt DEAL.

\section{Declarations}

Conflict of interest The authors declare that they have no conflict of interest.

Open Access This article is licensed under a Creative Commons Attribution 4.0 International License, which permits use, sharing, adaptation, distribution and reproduction in any medium or format, as long as you give appropriate credit to the original author(s) and the source, provide a link to the Creative Commons licence, and indicate if changes were made. The images or other third party material in this article are included in the article's Creative Commons licence, unless indicated otherwise in a credit line to the material. If material is not included in the article's Creative Commons licence and your intended use is not permitted by statutory regulation or exceeds the permitted use, you will need to obtain permission directly from the copyright holder. To view a copy of this licence, visit http://creativecommons.org/licenses/by/4.0/.

Publisher's Note Springer Nature remains neutral with regard to jurisdictional claims in published maps and institutional affiliations. 